\title{
Vascular Endothelial (VE)-Cadherin, Endothelial Adherens Junctions, and Vascular Disease
}

\author{
Maria Grazia Lampugnani, ${ }^{1,2}$ Elisabetta Dejana, ${ }^{1,3}$ and Costanza Giampietro ${ }^{1}$ \\ ${ }^{1}$ Fondazione Italiana per la Ricerca sul Cancro (FIRC) Institute of Molecular Oncology, 20139 Milan, Italy \\ ${ }^{2}$ Mario Negri Institute for Pharmacological Research, 20156 Milan, Italy \\ ${ }^{3}$ Department of Immunology, Genetics and Pathology, Uppsala University, 75185 Uppsala, Sweden \\ Correspondence: mariagrazia.lampugnani@ifom.eu; elisabetta.dejana@ifom.eu; costanza.giampietro@ifom.eu
}

Endothelial cell-cell adherens junctions (AJs) supervise fundamental vascular functions, such as the control of permeability and transmigration of circulating leukocytes, and the maintenance of existing vessels and formation of new ones. These processes are often dysregulated in pathologies. However, the evidence that links dysfunction of endothelial AJs to human pathologies is mostly correlative. In this review, we present an update of the molecular organization of $\mathrm{AJ}$ complexes in endothelial cells (ECs) that is mainly based on observations from experimental models. Furthermore, we report in detail on a human pathology, cerebral cavernous malformation (CCM), which is initiated by loss-of-function mutations in the genes that encode the three cytoplasmic components of AJs (CCM1, CCM2, and CCM3). At present, these represent a unique example of mutations in components of endothelial AJs that cause human disease. We describe also how studies into the defects of AJs in CCM are shedding light on the crucial regulatory mechanisms and signaling activities of these endothelial structures. Although these observations are specific for CCM, they support the concept that dysfunction of endothelial AJs can directly contribute to human pathologies.

In the endothelium of established blood vessels, cell-cell junctions connect and coordinate the activities of the individual endothelial cells (ECs) for the control of vascular permeability, immune cell trafficking, and angiogenesis (Table 1) (Dejana and Vestweber 2013). To accomplish these functions, endothelial cell-cell junctions need to be structurally and functionally dynamic (Millan et al. 2010; van Buul and Timmerman 2016). Under physiological situations, such plasticity is tightly controlled, although should this regulation be loosened, this can cause or exacerbate pathological condi- tions. The cell-cell junctions in the endothelium are defined as tight junctions and adherens junctions (AJs), which are intermixed in ECs (Vorbrodt and Dobrogowska 2003; Dejana 2004; Vestweber et al. 2009), in contrast to their strict apical-basal distribution in epithelial cells. Tight junctions provide strict control of vessel permeability, as is required in particular for the blood-brain barrier (Abbott et al. 2006; Banks 2016; Park-Windhol and D'Amore 2016).

In this review, we mainly report on the latest findings relating to the structure and regulation of homotypic AJs, which are ubiquitous along

Editors: Carien M. Niessen and Alpha S. Yap

Additional Perspectives on Cell-Cell Junctions available at www.cshperspectives.org

Copyright (C) 2018 Cold Spring Harbor Laboratory Press; all rights reserved; doi: 10.1101/cshperspect.a029322

Cite this article as Cold Spring Harb Perspect Biol 2018;9:a029322 
M.G. Lampugnani et al.

Table 1. Endothelial functions that require VE-cadherin

\begin{tabular}{|c|c|c|}
\hline Function & System & Activities \\
\hline Vessel organization & - & $\begin{array}{l}\text { During embryogenesis: in mouse (Carmeliet et al. 1999) and } \\
\text { zebrafish (Montero-Balaguer et al. 2009) }\end{array}$ \\
\hline $\begin{array}{l}\text { Polarity and lumen } \\
\text { formation }\end{array}$ & - & $\begin{array}{l}\text { In vitro cultured ECs and in vivo during embryogenesis } \\
\text { (Lampugnani et al. 2010) }\end{array}$ \\
\hline Proliferation & Inhibition & In vitro cultured ECs (Giampietro et al. 2012) \\
\hline Migration & Inhibition & $\begin{array}{l}\text { In vitro cultured ECs and in vivo mouse models (Giampietro et al. } \\
\text { 2012) }\end{array}$ \\
\hline $\begin{array}{l}\text { Protection from } \\
\text { apoptosis }\end{array}$ & - & $\begin{array}{l}\text { In vitro cultured ECs (Giampietro et al. 2012) and in vivo in mouse } \\
\text { embryo (Carmeliet et al. 1999) }\end{array}$ \\
\hline Mechanosensing & - & $\begin{array}{l}\text { In vitro cultured ECs and in vivo in association with Pecam-1, } \\
\text { VEGFR2, and VEGFR3. VE-cadherin does not directly } \\
\text { transduce mechanical forces, but it is essential for downstream } \\
\text { signaling (Tzima et al. 2005; Coon et al. 2015) }\end{array}$ \\
\hline \multirow[t]{4}{*}{ Control of permeability } & $\begin{array}{l}\text { In stabilized } \\
\text { vessels }\end{array}$ & $\begin{array}{l}\text { In vivo, in vasculature exposed to high mechanical stress (Corada } \\
\text { et al. 1999; Frye et al. 2015); not required in brain and skin (Frye } \\
\text { et al. 2015) }\end{array}$ \\
\hline & $\begin{array}{l}\text { In response to } \\
\text { VEGF }\end{array}$ & $\begin{array}{l}\text { In vivo through the Tsad/VEGFR2/Src complex (Sun et al. 2012) } \\
\text { and Src-mediated phosphorylation of VE-cadherin Y658 }\end{array}$ \\
\hline & $\begin{array}{l}\text { In response to } \\
\text { bradykinin }\end{array}$ & $\begin{array}{l}\text { In vitro and in vivo through Src-mediated phosphorylation of } \\
\text { VE-cadherin on Y658 and Y685 (Orsenigo et al. 2012) }\end{array}$ \\
\hline & $\begin{array}{l}\text { In response to } \\
\text { histamine }\end{array}$ & $\begin{array}{l}\text { In vivo through phosphorylation of VE-cadherin Y685 (Wessel } \\
\text { et al. 2014) }\end{array}$ \\
\hline $\begin{array}{l}\text { Control of } \\
\text { transmigration }\end{array}$ & - & $\begin{array}{l}\text { In vivo the stabilization of the VE-cadherin/ } \beta \text {-catenin complex } \\
\text { blocks leukocyte extravasation (Schulte et al. 2011). In vivo } \\
\text { dephosphorylation of VE-cadherin on Y731 enables leukocyte } \\
\text { diapedesis (Wessel et al. 2014) }\end{array}$ \\
\hline
\end{tabular}

the vascular tree (for heterotypic cell-cell junctions between ECs and cells of either the vascular wall or the tissue stroma, see Armulik et al. 2011). We also discuss a human vascular disease in which mutations of the components of endothelial AJs have a causal role in the human pathology.

\section{ENDOTHELIAL AJs: ACTORS AND INTERACTIONS}

The molecular organization of endothelial AJs has been described in detail in many previous reviews (Vestweber et al. 2009; Dejana and Giampietro 2012; Giannotta et al. 2013). Therefore, this section focuses specifically on new interactors and regulators of endothelial AJs (Fig. 1). These represent potential therapeutic targets to correct barrier and angiogenesis defects in several pathologies, including chronic inflammation, atherosclerosis, and tumors.
Vascular Endothelial Cadherin: Adhesive

Receptor and Signaling Mediator

Homophilic adhesion between vascular endothelial (VE)-cadherin molecules is crucial for the organization of the nascent vascular network (Carmeliet et al. 1999; Montero-Balaguer et al. 2009). Although homophilic adhesive recognition between VE-cadherin molecules does not require the VE-cadherin cytoplasmic tail (Navarro et al. 1995; Baumgartner et al. 2000), this domain is essential for junction stabilization and for tethering of an increasingly wide collection of cytoplasmic molecules that have scaffold functions and/or enzymatic activities. Recruitment of small GTPases and their guanine nucleotide exchange factors (GEFs) and GTPase-activating proteins (GAPs) is particularly crucial here, as these define the local cortical versus radial organization of the actin fibers, thus regulating the plasticity of the cell-cell junctions. 
A

NASCENT ADHERENS JUNCTION

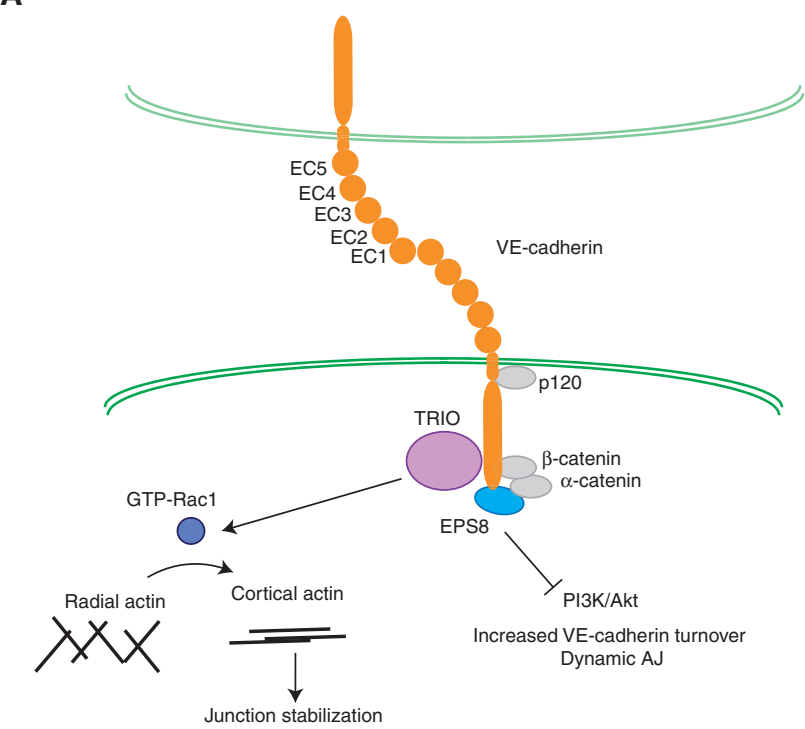

B

STABILIZED ADHERENS JUNCTION

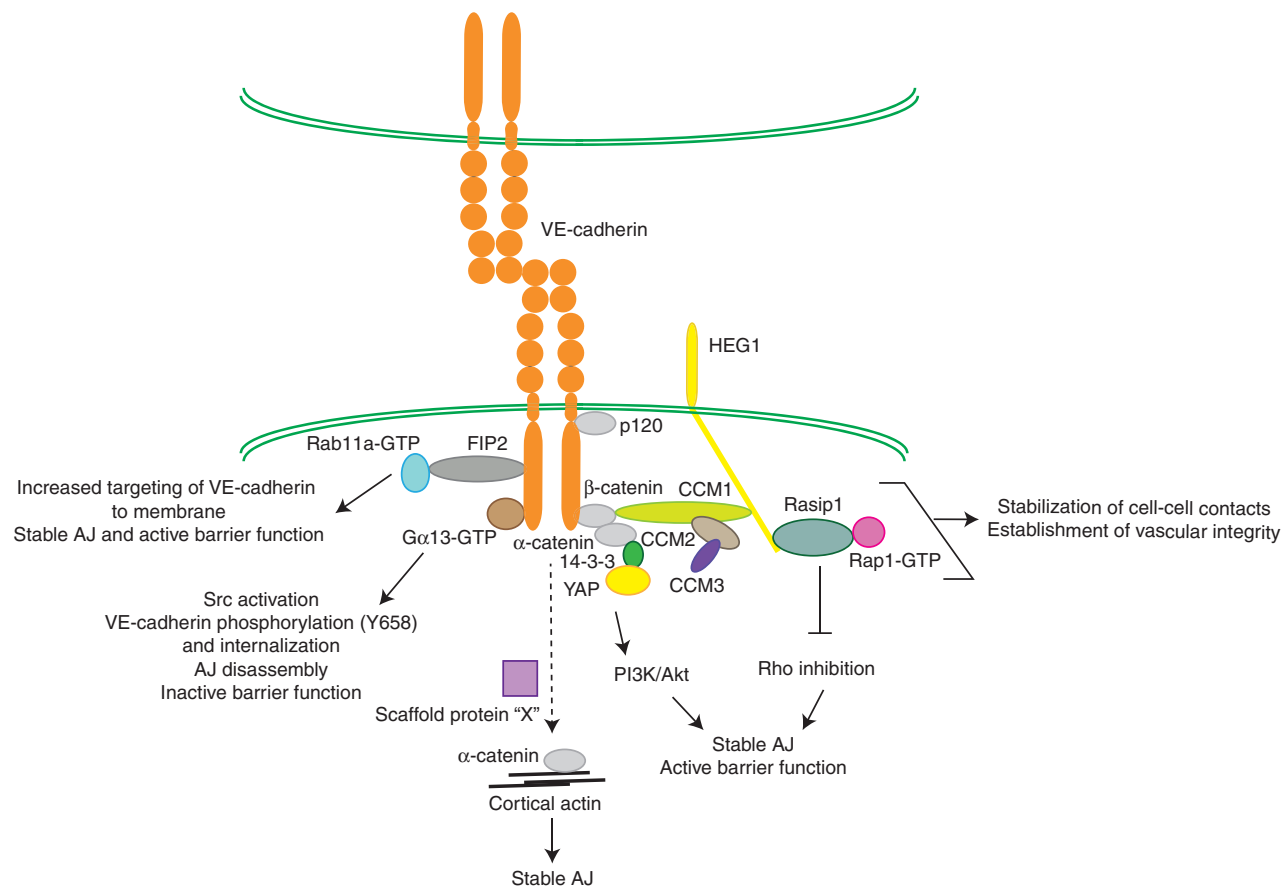

Figure 1. New interactors of endothelial adherens junctions (AJs). Recently described interactors of VE-cadherin complexes and their functions in nascent $(A)$ and stabilized $(B)$ endothelial AJs are represented as discussed in the text. In addition, in $(A)$, the binding of EGF receptor kinase substrate 8 (EPS8) to the AJ complex is shown to inhibit the phosphatidylinositol-3-kinase (PI3K)/AKT (protein kinase B) pathway, thus increasing VE-cadherin turnover at AJs (Giampietro et al. 2015) and maintaining dynamic AJs. Conversely, in stabilized AJs (B), the active PI3K/AKT pathway induces phosphorylation and cytoplasmic localization of the Yes-associated protein (YAP), which localizes to junctions and contributes to enhanced barrier function. As discussed in the text and shown in $B$, Rasip1 is required during stabilization of cell-cell contacts, but it is not necessary for their maintenance. The representation of the VE-cadherin domains interacting in trans (EC1-EC1) and in cis (EC1-EC2) are according to Harrison et al. (2011) and Brasch et al. (2012). 
M.G. Lampugnani et al.

The interaction of VE-cadherin with $\alpha$-catenin occurs through $\beta$-catenin, which is fundamental to dynamically engage the cytoskeleton (Vestweber et al. 2009; Dorland and Huveneers 2016). This was shown in mice in which VEcadherin was genetically replaced by a VEcadherin- $\alpha$-catenin fusion protein (Schulte et al. 2011). These mice had strongly stabilized endothelial junctions that were resistant to induction of vascular leakage by vascular endothelial growth factor (VEGF) or histamine. Several actin-binding molecules can mediate the binding between actin and $\alpha$-catenin at AJs (e.g., $\alpha$ actinin, vinculin, ZO1, afadin, and more recently in ECs, Arp2/3 [Abu Taha and Schnittler 2014; Abu Taha et al. 2014], eplin [Chervin-Petinot et al. 2012] and EPS8 [Giampietro et al. 2015]).

VE-cadherin can also form complexes with distinct transmembrane signaling systems, such as the endothelial-specific VEGF receptor-2 (VEGFR2), the vascular endothelial phosphotyrosine phosphatase (VE-PTP), the transforming growth factor (TGF) $\beta$ receptor complex, and the fibroblast growth factor receptor-1 (FGFR1). These complexes are important in the regulation of the activities of these systems at cell-cell junctions (Nawroth et al. 2002; Lampugnani et al. 2006; Rudini et al. 2008; Giampietro et al. 2012; Sun et al. 2012).

Finally, VE-cadherin can control signaling through limiting the nuclear translocation of catenins and other proteins that modulate cell transcription (Taddei et al. 2008; Giampietro et al. 2015).

\section{Novel "Interactors" of Endothelial Adherens Junctions}

During the last few years, several new components of AJs in ECs have been identified that define distinct functional complexes at AJs (Niessen and Gottardi 2008; Millan et al. 2010; Pannekoek et al. 2014; Giampietro et al. 2015; for a review, see Yap et al. 2015). We discuss some of these below (Fig. 1).

\section{Trio: A Rac1-GEF}

Rac1 is a key regulator of AJ formation, stabilization and plasticity. This small GTPase can promote opposite effects at endothelial AJs, which depend on the state of the AJs (i.e., established versus nascent) and on the type of stimulus. For a comprehensive review on this issue, see van Buul and Timmerman (2016).

Recently, the Rac1-GEF Trio was identified as a new component of AJs, and it was shown to directly bind to a region of the cytoplasmic tail of VE-cadherin (but not of $\mathrm{N}$-cadherin) that is proximal to the $\beta$-catenin-binding domain (Timmerman et al. 2015). This interaction is transient and occurs during AJ recovery after treatment with permeability-increasing agents. Recruitment of Trio by VE-cadherin triggers spatiotemporally restricted activation of Rac1, which in turn stabilizes AJs. Importantly, loss of Trio in ECs decreases AJ integrity and increases the number of focal AJs (i.e., the sites of junction remodeling), thereby increasing endothelial permeability in vitro. Intriguingly, Trio expression is increased in the vessel wall of patients with rheumatoid arthritis (Van Rijssel et al. 2013). In this pathology, ECs show up-regulated adhesion molecules, such as E-selectin, vascular cell adhesion molecule (VCAM), and intercellular adhesion molecule (ICAM), which are markers of inflammation. In parallel, ECs show actin cytoskeleton remodeling and down-regulation of junctional molecules, thus impairing barrier function (Cain et al. 2010). The increase in Trio in rheumatoid arthritis might thus represent a feedback mechanism to counteract weakening of the endothelial junctions.

\section{G-Protein $\alpha 13$}

Go13 is a member of the heterotrimeric $G$ protein family that transduces signals from Gprotein-coupled receptors through interactions with downstream effectors. G $\alpha 13$ also serves other functions independent of its coupling to G-protein-coupled receptors (Kelly et al. 2008), as it can induce VEGFR2, which thus increases endothelial responsiveness to VEGFA (Sivaraj et al. 2013). Mice with EC-specific loss of Go13 showed reduced VEGFR2 expression at sites of angiogenesis, and attenuated VEGF effects, which resulted in impaired retinal angiogenesis (Sivaraj et al. 2013). 
Recently, it was shown that in response to proinflammatory signals, active (i.e., GTP-

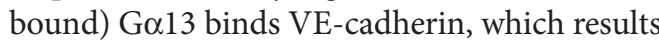
in AJ disassembly (Gong et al. 2014). The Go13/ VE-cadherin complex can bind and activate Src, which promotes phosphorylation of VE-cadherin on Y658 (Orsenigo et al. 2012), and its subsequent internalization. Importantly, Go13-dependent disassembly of AJs also increases endothelial permeability and leukocyte transmigration in vivo (Gong et al. 2014).

\section{EGF Receptor Kinase Substrate 8}

EGF receptor kinase substrate 8 (EPS8) is an adaptor protein that has been shown to transduce signals from Ras to Rac (Scita et al. 1999). This protein caps the fast growing ends of actin filaments, thus influencing the actin polymerization/depolymerization rates (Hertzog et al. 2010). EPS8 is also important for the correct organization of actin-based structures, for the migratory properties of dendritic cells (Frittoli et al. 2011), and for intracellular trafficking of membrane receptors (Auciello et al. 2013). Recently, EPS8 was shown to be a direct, but transient, interactor of VE-cadherin during junctional remodeling (Giampietro et al. 2015). EPS8 is localized at cell-cell contacts in subconfluent ECs, whereas it is absent from junctions in confluent EC monolayers. Expression of EPS8 results in increased turnover of VE-cadherin, probably through indirect regulation of phosphorylation of VE-cadherin on S665, and the subsequent ubiquitination of VE-cadherin (Gavard and Gutkind 2006). Finally, EPS8 is a regulator of EC barrier function: Eps8 knockout mice show increased vascular permeability selectively for small-size tracers, such as cadaverine (Giampietro et al. 2015).

\section{Yes-Associated Protein}

Several studies have recently provided new insights into transcriptional regulation by the VE-cadherin complex. For example, the transient interaction of EPS8 with VE-cadherin promotes nuclear translocation and transcriptional activity of the Yes-associated protein (YAP)
(Giampietro et al. 2015). This cotranscriptional regulator was originally characterized as the molecular target of the Hippo pathway (Varelas 2014) and it is a key relay for the transmission of mechanical inputs into transcriptional programs (Dupont et al. 2011).

During maturation of endothelial junctions in vitro, YAP is phosphorylated through activation of the phosphatidylinositol-3-kinase (PI3K)/Akt (protein kinase B) pathway (Choi et al. 2015; Giampietro et al. 2015). This results in nuclear exclusion of YAP, and its redistribution to AJs, where it interacts with VE-cadherin through the $\alpha$-catenin/ 14-3-3 complex (Giampietro et al. 2015), and remains associated with stable junctions. Consistently, YAP colocalizes with VE-cadherin in vivo in the endothelium of brain and retina blood vessels, which require strict control of permeability. In contrast, in blood vessels characterized by loose junctions, as in organs such as the kidney, liver, and spleen, colocalization of YAP and VE-cadherin is very limited (Giampietro et al. 2015). Furthermore, YAP-deficient mice show an early embryonic lethal phenotype caused by defects in yolk-sac vasculogenesis, chorio-allantoic fusion, and embryonic axis elongation (Morin-Kensicki et al. 2006). Together, these data indicate an important physiological function for endothelial YAP in the organization and stabilization of endothelial junctions, and thus of the endothelial barrier; this deserves further characterization.

\section{Heart-of-Glass and Ras-Interacting Protein 1}

Heart-of-glass (HEG1) is an orphan receptor that is expressed in ECs and that supports vessel formation and stability. Heg1 ${ }^{-/-}$mice show defective integrity of the heart, and of the blood and lymphatic vessels (Kleaveland et al. 2009). HEG1 binds to CCM1, one of the three cytoplasmic components of AJs (i.e., CCM1, CCM2, CCM3) that show loss-of-function mutations in the human pathology known as cerebral cavernous malformation (CCM; for further details, see section on human vascular pathologies and mutations). This binding occurs through the 19 carboxy-terminal residues of the intracellular tail of HEG1 (see section on human vascular 
M.G. Lampugnani et al.

pathologies). In this way, HEG1 functions with the CCM complex in a common signaling pathway that is required for heart and vascular development (Gingras et al. 2012). However, unlike deletion of the $\mathrm{Ccm}$ genes, deletion of Heg1 in early postnatal mice does not induce cavernoma lesions in the central nervous system (which are seen in CCM). In addition, to date, mutations of HEG1 have not been reported for patients with CCM (Zheng et al. 2014).

The endothelial-specific adaptor protein Ras-interacting protein 1 (Rasip1) is a Rap1 effector that is essential for vascular integrity and development (Xu et al. 2011; Post et al. 2013; Wilson et al. 2013). Recently, Rasip1 was shown to interact directly with HEG1 (across nine critical residues in the carboxy-terminal region of HEG1), and to localize to assembling AJs, to establish vascular integrity (de Kreuk et al. 2016). In agreement with this, Rasip1 is crucial for embryonic vessel formation (Xu et al. 2011) and for stabilization of EC cell-cell contacts. In Rasip1 knockout mice, the vessels initially form, but they become unstable and focally hemorrhagic, which results in embryonic lethality (Wilson et al. 2013). Interestingly, Rasip1 binding to HEG1 is necessary for Rasip 1 translocatation to EC cell-cell contacts and for stabilization of endothelial junctions. This suggests that HEG1 represents a physical nexus for Rap1 signaling at AJs during vascular remodeling (de Kreuk et al. 2016). How HEG1 localization to EC cell-cell junctions is regulated remains to be determined.

Transmembrane Molecules Associated with VE-Cadherin: Kinase Receptors and the Tyrosine Phosphatase VE-PTP

\section{Kinase Receptors}

Several transmembrane kinase receptors can associate with VE-cadherin, including VEGFR2, TGF $\beta$ receptor-2, FGFR1, and, as recently reported, VEGFR3 (Coon et al. 2015). Depending on the junctional state, these receptors can recruit different downstream signal transduction complexes that can either protect the ECs from apoptosis (via activation of PI3K in stable junctions), or promote EC proliferation (via activa- tion of the $\mathrm{p} 42 / 44$ mitogen-activating protein kinase in weak/dynamic junctions) (Carmeliet et al. 1999; Lampugnani et al. 2006; Rudini et al. 2008; Giampietro et al. 2012; for review, see Bravi et al. 2014).

The VEGFR2/ VE-cadherin AJ complex controls VEGFA-induced permeability through the T-cell-specific adaptor protein TSAd, which regulates the activation of Src signaling (Sun et al. 2012). VEGFA-induced phosphorylation of VEGFR2 on Y949 (Y951 in humans) is crucial for the binding between TSAd and Src. This also further promotes phosphorylation of Src at Y418, and of VE-cadherin at Y658 and Y685, which leads to increased vascular permeability (Eliceiri et al. 1999; Sun et al. 2012; Gong et al. 2014; Vestweber et al. 2014; Gordon et al. 2016; Li et al. 2016). In agreement with this, mice that express a phosphorylation-resistant mutant of VEGFR2 (VEGFR2 ${ }^{\mathrm{Y} 949 \mathrm{~F} / \mathrm{Y} 949 \mathrm{~F}}$ ) show reduced vascular leakage in tumors and decreased metastatic spread, owing to inhibition of tumor cell intravasation. These mice also show improved responses to chemotherapy ( $\mathrm{Li}$ et al. 2016). In addition, TSAd is required for VEGF-mediated angiogenic sprouting, but not for vasculogenesis (Gordon et al. 2016).

VEFGR2 and VEGFR3 directly interact with VE-cadherin through their transmembrane domains (Coon et al. 2015), which results in ligand-independent activation of these tyrosine kinase receptors, through their phosphorylation by the Src family kinases. This effect is particularly important for mechanotransduction of fluid shear-stress that is mediated by the junctional mechanosensory complex (Jin et al. 2003; Tzima et al. 2005; Galvagni et al. 2010; Coon et al. 2015) that consist of PECAM1, VE-cadherin, VEGFR2, and VEGFR3 (Coon et al. 2015).

In vivo, recruitment of these receptors to endothelial junctions can vary, depending on the specific hemodynamic features of the vascular districts. For example, VEGFR3 is linked to VE-cadherin in a mechanosensory complex that is particularly associated with areas of the aorta that are exposed to disturbed blood flow, or are prone to develop inflammation and atherosclerotic plaques in hypercholesterolemia (Coon et al. 2015). Deletion of VEGFR3 in mice reduc- 
es the fibronectin and VCAM markers of endothelial inflammation in these areas.

\section{Vascular Endothelial Phosphotyrosine Phosphatase and Tie2}

VE-PTP is a tyrosine phosphatase that is specifically expressed by ECs. VE-PTP works in concert with the angiopoietin tyrosine kinase receptor Tie2 (Fachinger et al. 1999). Angiopoietin1 induces localization of the VE-PTP/ Tie2 complex to junctions (Fukuhara et al. 2008; Saharinen et al. 2008).

At AJs, VE-PTP dephosphorylates VE-cadherin (at Y658, Y685, Y731) (Gong et al. 2015), which prevents VE-cadherin internalization, and thus stabilizes the AJs (Nawroth et al. 2002; Nottebaum et al. 2008). In addition, VEPTP dephosphorylates plakoglobin (Nottebaum et al. 2008), and the two receptor kinases Tie2 and VEGFR2 (at Y658), thereby decreasing their kinase activities (Mellberg et al. 2009; Hayashi et al. 2013). VE-PTP needs to dissociate from VE-cadherin for increased EC permeability (Broermann et al. 2011). Adhesion of lymphocytes to EC via VCAM, and VEGF-activated VEGFR2, stimulate Rac-dependent generation of reactive oxygen species by the $\mathrm{NAD}(\mathrm{P}) \mathrm{H}$ oxidase NOX. These reactive oxygen species then activate the redox-sensitive, proline-rich tyrosine kinase Pyk2. It has been inferred that activated Pyk2 can phosphorylate a VE-PTP substrate, the nature of which has yet to be determined. This would then transmit conformational changes to the extracellular domain of VE-PTP, to promote the detachment of VEPTP from VE-cadherin (Vockel and Vestweber 2013). As a consequence, VE-cadherin and its associated molecules can be phosphorylated and the AJs are destabilized.

The expression of VE-PTP is transcriptionally regulated by hypoxia-inducible factor $2 \mathrm{a}$ (HIF2a). HIF2a-deficient mice show low levels of VE-PTP expression that are accompanied by increased VE-cadherin phosphorylation, which result in loss of AJ integrity and impaired endothelial barrier function (Gong et al. 2015).

Recently, the role of VE-PTP in VE-cadherin-mediated and Tie2-mediated strengthen- ing of AJs was further defined. The association of VE-PTP with VE-cadherin reinforces AJ integrity, whereas the association of VE-PTP with Tie2 decreases the junction-stabilizing activity of Tie2. In adult vessels, a VE-cadherin/ active VE-PTP complex acts as a "safety net" that stabilizes endothelial junctions if Tie2 activity is impaired, as observed in lipopolysaccharide-induced pulmonary inflammation in mice (Frye et al. 2015).

These studies have also suggested that in established vessels, VE-cadherin is required to maintain junction stability in vascular districts exposed to high mechanic stress, like in the lungs and heart, as also previously reported (Corada et al. 1999), although it is not essential in other regions, like the brain and skin. Accordingly, the pharmacological inhibitor of the catalytic activity of VE-PTP, AKB-9778, prevents ocular neovascularization in mice by activating Tie2 and inhibiting the barrier destabilizing effects of VEGF (Shen et al. 2014). A similar compensatory role of VE-PTP inhibition was reported in a murine model of cerebral stroke (Gurnik et al. 2016). In addition, a junction-stabilizing role of Tie2 has been reported recently for patients suffering from acute respiratory distress syndrome, a severe condition that is characterized by the accumulation of liquid and immune cell infiltrate in the lungs, which often occurs as a consequence of infection (Ghosh et al. 2016). Genetic single nucleotide polymorphism variants of Tie2 that decrease expression of Tie2 in humans are associated with increased risk of acute respiratory distress syndrome. In parallel studies in animal models, mice with only a single Tie 2 allele showed more severe vascular leakage and higher mortality after experimental sepsis than wild-type mice.

\section{THE ACTIVITY OF SMALL GTPases AT ENDOTHELIAL ADHERENS JUNCTIONS}

\section{Rap1 and Local Regulation of the Actin Cytoskeleton}

The small GTPase Rap1 is a master modulator of endothelial junction plasticity and vascular stability. EC-specific Rap1a and Rap1b double 
M.G. Lampugnani et al.

knockout mice in a pure C57Bl6 genetic background are embryonically lethal, with localized hemorrhages at midgestation (ChrzanowskaWodnicka et al. 2015). In addition, through stabilization of cell-cell junctions, Rap1 inhibits immune-cell transmigration (Wittchen et al. 2005; Wittchen and Hartnett 2011). Furthermore, the Rap-GEFs PDZ-GEF and Epac activate Rap1 and stabilize endothelial AJs under basal conditions and in response to cAMP-increasing agents (Pannekoek et al. 2011).

Two related small GTPase-activated kinases have important roles in the signaling of Rap1 at AJs: myotonic dystrophy kinase-related Cdc42binding kinase (MRCK), which contain a Cdc42-/Rac1-binding domain; and Rho-associated protein kinase (ROCK), which contains a Rho-binding domain (Zhao and Manser 2015). Rap1 stabilizes cell-cell contacts by recruiting FGD5 to the junctions, which is a Cdc42-GEF (Ando et al. 2013). At the junctions, FGD5 can activate $\mathrm{Cdc} 42$ and thus promote $\mathrm{Cdc} 42-$ MRCK-nMII (nonmuscle myosin II)-dependent cortical actin bundling (Zhao and Manser 2015). Indeed, EC-selective Cdc42 knockout inhibited angiogenesis and induced aberrant vascular remodeling, with defective F-actin organization and disorganized cell-cell junctions (Barry et al. 2015). In addition, Rap1 inhibits not only Rho-ROCK-nMII to constrain the formation of radial actin stress fibers, but also actomyosin contraction, through inhibition of the Rho-ROCK-dependent phosphorylation of myosin light chain kinase (Ando et al. 2013; Wilson and Ye 2014). The mechanisms through which Rap1 inhibits these two Rho-Rock actions have recently been partially elucidated (Fig. 2). It has recently been shown that HEG1 not only binds CCM1 but also binds Rasip1, and that both Rasip1 and CCM1 can bind HEG1 only if they are bound to active (i.e., GTPbound) Rap1 (de Kreuk et al. 2016) (see section on endothelial AJs). When Rasip1 and its related protein Radil are bound to GTP-bound Rap1, they localize to the plasma membrane and inhibit Rho activity by recruiting the Rho-GAP ArhGAP29 (Xu et al. 2011; Post et al. 2013, 2015). Although Radil is required for membrane localization of ArhGAP29, Rasip1 is mainly re- quired for the ArhGAP29 activity (Post et al. 2015). All of this mutual and sequential activation and inhibition results in local regulation of actin stress fibers, and thus either stabilization or destabilization of EC cell-cell contacts. In addition, in the absence of Rasip1 or Radil, both $\beta$-catenin (Post et al. 2013) and VE-cadherin (Xu et al. 2011) dissociate from AJs. The consequence is inhibition of both barrier function (Post et al. 2013) and tubulogenesis (Xu et al. 2011).

VE-cadherin further contributes to the local organization of the actin cytoskeleton through $\beta$-catenin-dependent binding of CCM1 and its localization of Rap1 (Glading et al. 2007). At the same time, VE-cadherin can regulate the localization of Rap1 GEFs to junctions (e.g., Epac, PDZ-GEF; see section on Rap1 and local regulation of the actin cytoskeleton), thus regulating the local activation of Rap1 (Pannekoek et al. 2011). Notably, Epac cannot stabilize endothelial contacts in VE-cadherin knockout ECs (Kooistra et al. 2005). In addition, VE-cadherin binds directly to the GEF Trio, which in turn activates Racl and RhoG (through the Trio amino-terminal domain) and RhoA (through the Trio carboxy-terminal domain) (Bellanger et al. 1998; Timmerman et al. 2015). In particular, Trio-dependent activation of Rac induces the formation of cortical actin bundles and stabilizes EC cell-cell contacts.

How Does Inflammation Impinge on Small GTPase-Directed Regulation of Endothelial Adherens Junctions?

Inflammatory mediators, such as cytokines, adherent leukocytes, and growth factors, stimulate the formation of radial stress fibers and actomyosin contraction, which can result in junction retraction. As a consequence, AJs become discontinuous and "focal." Such focal AJs are the sites of anchorage of the radial actin stress fibers that connect with stress fibers from adjacent cells (Millan et al. 2010). Focal AJs promote increased passage of solutes and fluids through the junctional gaps that are formed (i.e., paracellular permeability), and they also generate the tension that guides migrating leukocytes toward areas of 
VE-Cadherin, Endothelial AJs, and Vascular Disease

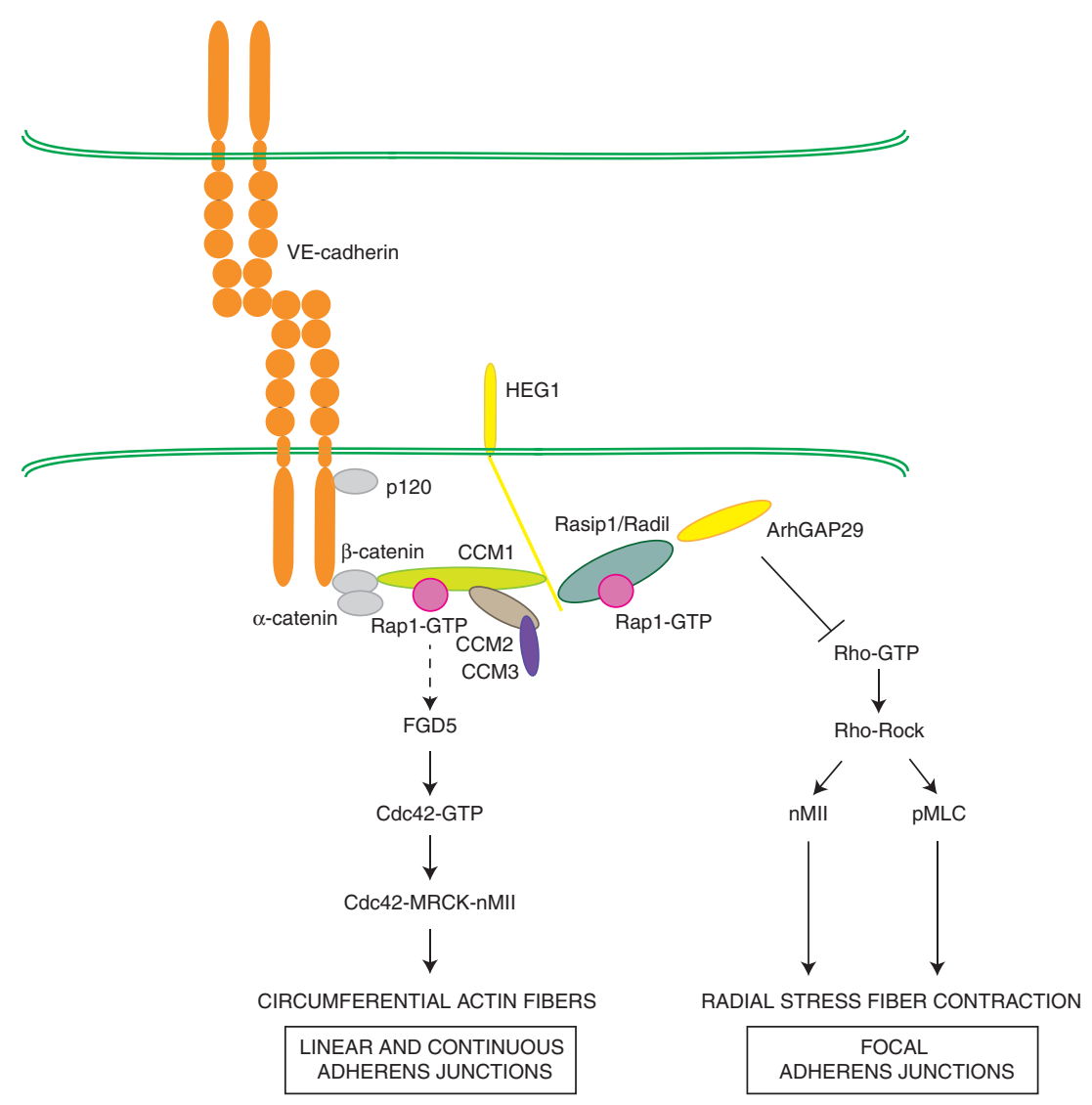

Figure 2. Rho-GTPases associated with adherens junctions (AJs) control the actin cytoskeleton dynamics and junction stability in endothelial cells (ECs). Schematic representation of the interactions, activities, and regulation of the RhoGTPases, as discussed in the text. Rap1-GTP promotes linear and continuous AJs, with both inducing circumferential actin fibers and inhibiting Rho-GTP, which instead supports focal AJs and cell-cell retraction. Dashed lines indicate that some intermediate steps remain to be defined.

"easy passage" for transmigration (Huveneers et al. 2012; for review, see Marcos-Ramiro et al. 2014). These areas often correspond to soft junctional regions (Schaefer and Hordijk 2015). Rho-GTPases control both transcellular and paracellular transmigration (Heemskerk et al. 2014; Timmerman et al. 2016). With nonpathological transmigration, this paracellular passage is very well coordinated, with the reestablishment of EC cell-cell junctions that prevent any increase in permeability. This control requires local activation of RhoA and ROCK2b in ECs, to organize the contractile basolateral actomyosin structures around the transmigrating leukocytes. These endothelial "elastic sheaths" or pores are controlled by ICAM, which organizes and recruits the RhoGEFs, LARG, and Ect2. During paracellular diapedesis, these pores are localized to the junctions, and they prevent vascular leakage during leukocyte transmigration. VE-cadherin is strongly localized at the pore margins. However, its depletion does not affect pore integrity (Heemskerk et al. 2016; Muller 2016). In chronic inflammation, gaps between cells are not resealed, which not only results in enhanced transmigration, but also increased permeability.

ROCK inhibitors have been developed for potential therapeutic applications in cardiovascular diseases (see also section on cerebral 
M.G. Lampugnani et al.

cavernous malformation disease). However, their specificity still appears to be low and the effects elicited are variable, in which these depend on the shear stress conditions of the vascular district (Kolluru et al. 2014). Rap1 is a further attractive target in the treatment of cardiovascular diseases. At present, synthetic agonists and antagonists of its GEFs EPAC1 and EPAC2 have been developed and are being tested extensively in cultured cells, although their biological effects in vivo require further investigation (Schwede et al. 2015; Lezoualc'h et al. 2016).

\section{HUMAN VASCULAR PATHOLOGIES AND MUTATIONS IN COMPONENTS OF ENDOTHELIAL ADHERENS JUNCTIONS}

Mutations in genes that encode core endothelial junction proteins are rare among the several gene mutations that trigger human vascular pathologies (Nguyen et al. 2014) (see ncbi.nlm.nih. gov/clinvar/). For example, mutations in VEcadherin have been reported in human diseases. CCM is thus far the only human disease in which components of endothelial AJs are mutated, which results in disorganized AJs in patients with CCM.

Cerebral Cavernous Malformation: Scaffold Molecules That Regulate Signaling at

Endothelial Adherens Junctions

CCM1, CCM2, and CCM3 are cytoplasmic scaffold proteins that are found at endothelial AJs in association with HEG1 and $\beta$-catenin (Kleaveland et al. 2009; Gingras et al. 2012; Zhou et al. 2016b). Complexes between CCM1 and CCM2 are required for the AJ localization of these proteins (Stockton et al. 2010), while association of CCM3 with AJs was inferred from the demonstration that the CCMs can form a ternary complex (Voss et al. 2007) (for a structurally oriented analysis of the interactions among the CCMs, see Voss et al. 2009; Zheng et al. 2010; Fisher and Boggon 2014). In addition, CCM1, CCM2, and CCM3 can all be co-immunoprecipated with VE-cadherin (N Rudini, MG Lampugnani, and E Dejana, unpubl.).
The CCM proteins can form complexes with other non-CCM partners in various cellular compartments outside of AJs; for example, CCM3 at the Golgi complex, in association with STRIPAK (Fidalgo et al. 2010; Kean et al. 2011); and CCM1 in the nucleus, in association with integrin cytoplasmic domain-associated protein-1 (ICAP1) (Francalanci et al. 2009; Draheim et al. 2017). The CCMs can also regulate processes and pathways that have not yet been directly implicated in the regulation of EC cell-cell junctions and are therefore not discussed here, although these are important for the development of cavernomas. These include, for example, down-regulation of the MEKK3ERK5-Kruppel-like factor (Klf) 2/4 pathway (Cullere et al. 2015; Cuttano et al. 2016; Zhou et al. 2016b), and specifically for CCM3, inhibition of secretion of angiopoietin2 (Zhou et al. 2016a) and stabilization of VEGFR2 from endocytosis (He et al. 2010).

Loss-of-function mutations in CCM1, CCM2, and CCM3 result in both the inherited and the sporadic neurological pathologies of CCM. This disease is caused by vascular malformations that are seen as clusters of dilated microvessels in the central nervous system that are fragile, leaky, and prone to rupture, and which can produce focal neurological symptoms and hemorrhagic stroke.

The hereditary form of CCM is initiated by germ-line heterozygous mutations in any of the three CCM genes. The somatic loss of the second allele in ECs of the central nervous system then gives rise to cavernoma lesions (Gault et al. 2005; Akers et al. 2009). A similar somatic loss of heterozygosity for the Von Hippel-Lindau (VHL) gene has been described in VHL disease, which predisposes patients with an inherited single mutant allele to various types of cyst formation and tumors, as well as the vascular malformations, and in particular cerebellar hemangioblastomas (Gossage et al. 2015). In contrast to patients with VHL disease, only familial CCM3 patients show increased frequency of meningiomas, in addition to early vascular cavernomas (Riant et al. 2013). In sporadic CCM, which is the most frequent form of CCM, somatic mutations of the CCM genes are found 
exclusively in the cerebral cavernomas (McDonald et al. 2014).

As no pharmacological treatment is available for patients with CCM disease, a lot of effort is being devoted to an understanding of the molecular mechanisms that underlie this disease, to identify potential therapeutic targets.

\section{Cerebral Cavernous Malformation Disease: Translational Hints From Disorganized Adherens Junctions}

The CCM proteins do not only localize to junctions, as they also regulate the organization and function of EC cell-cell contacts. In patients, the cell-cell junctions are disorganized in the ECs of the cerebral cavernomas, both at the ultrastructural level (Clatterbuck et al. 2001) and through staining for VE-cadherin (Fig. 3) (Bravi et al. 2016). As human cavernoma samples are obtained during surgical resection of established lesions, the role of dysfunctional AJs in the development of cavernous lesions has been further verified in experimental models.
In murine models of CCM, the association of VE-cadherin and $\beta$-catenin to cell-cell junctions is impaired shortly after induction of endothelial-specific ablation of the C cm1, Ccm2, or Ccm3 genes (Boulday et al. 2011; Maddaluno et al. 2013; Bravi et al. 2015). This is an EC-autonomous response, as on silencing/ deletion of any of the three CCMs in cultured ECs, the localization of both junctional VEcadherin and $\beta$-catenin becomes disorganized (Glading et al. 2007; Boulday et al. 2011; Maddaluno et al. 2013; Bravi et al. 2015). These data thus suggest that endothelial AJs are significant early targets in the initiation of cavernoma lesions. Of note, the observation that VE-cadherin and $\beta$-catenin are disorganized under these conditions, together with the finding that $\mathrm{N}$ cadherin is expressed in the ECs of cavernomas from not only patients but also experimental in vivo and in vitro models of CCM, prompted the study of endothelial-to-mesenchymal transition in ECs of the cavernoma (Maddaluno et al. 2013; Bravi et al. 2015, 2016; Cuttano et al. 2016).

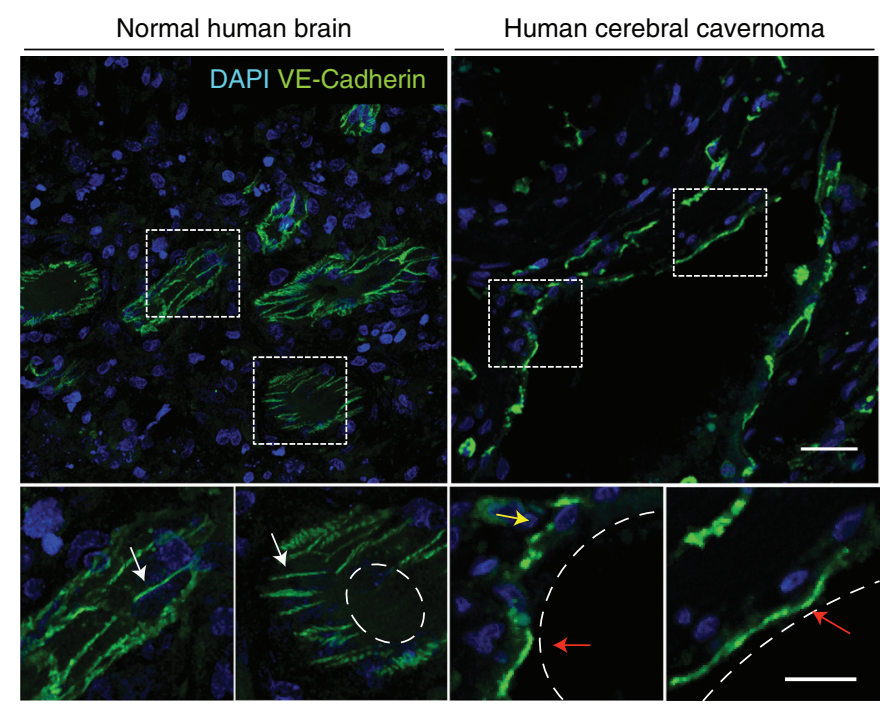

Figure 3. Endothelial adherens junctions (AJs) are dismantled in human cerebral cavernoma. VE-cadherin (green) labeled EC cell-cell junctions in normal human brain vessels (white arrows). In human cerebral cavernoma from a patient with cerebral cavernous malformation (CCM), the AJs appear to be dismantled and VEcadherin is ectopically distributed to the apical and basal surfaces (red and yellow arrows, respectively). Bottom panels show magnification of the boxed areas. Dashed lines outline the lumina. Scale bars, $100 \mu \mathrm{m}$ and $50 \mu \mathrm{m}$ (magnification panels). 
M.G. Lampugnani et al.

The mechanisms through which the CCMs regulate endothelial junctions are partially understood (Fig. 2). CCM1 is required for localization of Rap1 to cell-cell contacts (Glading et al. 2007), which stabilizes junctions by increasing junctional tension and inhibiting radial tension, as described in the section on Rap1 and local regulation of the actin cytoskeleton. (Pannekoek et al. 2014). In the absence of CCM1 or CCM2, Rap1 is lost from junctions, which results in increased Rho/ROCK signaling (Stockton et al. 2010) and reduced Cdc42 signaling (Whitehead et al. 2009). This thus leads to disorganization of endothelial junctions and increased permeability (Fig. 2) (Stockton et al. 2010).

The concept that dysfunctional endothelial AJs are significant mediators in the formation of cavernoma lesions is further supported by the effects of drugs that have been tested as potential pharmacological therapies for patients with CCM. At present, CCM can be treated only through surgical resection of symptomatic lesions. Fasudil is a ROCK inhibitor, and it has been used to counteract increased Rho activation, and to investigate its effects on the cytoskeleton and vascular permeability that result from CCM1 and CCM2 suppression in ECs in vitro, as well as in Ccm1 and Ccm2 haploinsufficient mice. Fasudil inhibits the formation and persistence of radial actin stress fibers, which promotes endothelial junction instability, while it restores circumferential actin bundles, thus rescuing permeability control (Stockton et al. 2010). Importantly, fasudil reduces the number and dimensions of cavernoma lesions in murine models of CCM1 and CCM2 disease (McDonald et al. 2012). Both fasudil and the weak, nonspecific, Rock inhibitor simvastatin also inhibit chronic hemorrhage in cavernomas in the same murine models (Shenkar et al. 2017).

Loss of either CCM1 or CCM3 has been shown to activate $\beta$-catenin-driven transcription (Glading and Ginsberg 2010) through a Wnt ligand-independent mechanism (Bravi et al. 2015), which is accompanied by decreased $\beta$-catenin at junctions. A similar Wnt-independent mechanism that drives $\beta$-catenin translocation to the nucleus after disorganization of cell contacts has been recently described during myogenesis in selected epithelial somite progenitor cells (Sieiro et al. 2016). Although it is not yet clear whether $\beta$-catenin can directly translocate from the junctions to the nucleus (Kam and Quaranta 2009), the decrease in junctional $\beta$-catenin has been reported to correlate with its increased transcriptional activity (Taddei et al. 2008; Glading and Ginsberg 2010; Bravi et al. 2015).

Sulindac sulfide and sulindac sulfone (exisulind) are two non-steroidal anti-inflammatory drugs that have been tested for inhibition of enhanced $\beta$-catenin-driven transcription after ablation of CCM1 and CCM3 (Glading and Ginsberg 2010; Bravi et al. 2015). Both of these compounds induced reorganization of AJs in Ccm1-, Ccm2-, and Ccm3-ablated ECs in culture (Bravi et al. 2015; L Bravi, E Dejana, and MG Lampugnani, unpubl.). They also reduced the numbers and dimensions of vascular malformations in brain and retina of endothelial-specific $\mathrm{Ccm} 3$ knockout mice, which were accompanied by increased VE-cadherin recruitment to AJs (Bravi et al. 2015).

As endothelial junctions are important targets of CCM activity, together with F-actin organization, their organization was used as a readout parameter in the primary step of automated imaging in a screening of $2100 \mathrm{com}$ pounds selected as potential drugs for treatment of CCM. Two of these, vitamin D3 and the superoxide scavenger tempol, rescued not only the structural phenotypes, but also the transcellular resistance after CCM2 silencing in human ECs cultured in vitro. Importantly, these compounds also decreased the cavernoma lesion burden in EC-restricted $\mathrm{Ccm} 2$ knockout mice (Gibson et al. 2015), which further implicates dysfunctional junctions in the pathogenesis of cavernoma lesions in CCM.

\section{CONCLUDING REMARKS}

The identification of the molecular components and underlying signaling mechanisms that controls the function of endothelial AJs has advanced enormously over the last few years. In contrast, how the dysfunction of these new AJ components contributes to human vascular 
diseases remains, with few exceptions, an important open issue for future research.

For clinical applications, it will be useful to collect systematic imaging data and molecular analysis of endothelial junctions in human pathologies, and to correlate the status of endothelial AJs with the stages of progression of CCM, and of the responses to specific therapies, in an open-access database. This knowledge would also further help to establish whether some junction components will serve in the future not only as routine diagnostic markers of endothelial junction pathology, but also as readouts for response to therapy; indeed, they might even become specific targets for therapy in these vascular diseases.

\section{ACKNOWLEDGMENTS}

This study was supported by the following grants to E.D.: Associazione Italiana per la Ricerca sul Cancro (AIRC IG 14471) and Special Program Molecular Clinical Oncology 5x1000 to AGIMM (AIRC Gruppo Italiano Malattie Mieloproliferative); TELETHON-GGP14149; Fondazione CARIPLO contract n. 2012-0678; Initial Training Networks (ITN) VESSEL, contract No. 317250; Brain Barriers Training (BtRAIN), contract No.675619; The Swedish Science Council; and The Knut and Alice Wallenberg Foundation.

\section{REFERENCES}

Abbott NJ, Ronnback L, Hansson E. 2006. Astrocyte-endothelial interactions at the blood-brain barrier. Nat Rev Neurosci 7: 41-53.

Abu Taha A, Schnittler HJ. 2014. Dynamics between actin and the VE-cadherin/catenin complex: Novel aspects of the ARP2/3 complex in regulation of endothelial junctions. Cell Adh Migr 8: 125-135.

Abu Taha A, Taha M, Seebach J, Schnittler HJ. 2014. ARP2/ 3-mediated junction-associated lamellipodia control VEcadherin-based cell junction dynamics and maintain monolayer integrity. Mol Biol Cell 25: 245-256.

Akers AL, Johnson E, Steinberg GK, Zabramski JM, Marchuk DA. 2009. Biallelic somatic and germline mutations in cerebral cavernous malformations (CCMs): Evidence for a two-hit mechanism of CCM pathogenesis. Hum Mol Genet 18: 919-930.

Ando K, Fukuhara S, Moriya T, Obara Y, Nakahata N Mochizuki N. 2013. Rap1 potentiates endothelial cell junctions by spatially controlling myosin II activity and actin organization. J Cell Biol 202: 901-916.

Armulik A, Genove G, Betsholtz C. 2011. Pericytes: Developmental, physiological, and pathological perspectives, problems, and promises. Dev Cell 21: 193-215.

Auciello G, Cunningham DL, Tatar T, Heath JK, Rappoport JZ. 2013. Regulation of fibroblast growth factor receptor signalling and trafficking by Src and Eps8. J Cell Sci 126: 613-624.

Banks WA. 2016. From blood-brain barrier to blood-brain interface: New opportunities for CNS drug delivery. Nat Rev Drug Discov 15: 275-292.

Barry DM, Xu K, Meadows SM, Zheng Y, Norden PR, Davis GE, Cleaver O. 2015. Cdc42 is required for cytoskeletal support of endothelial cell adhesion during blood vessel formation in mice. Development 142: 3058-3070.

Baumgartner W, Hinterdorfer P, Ness W, Raab A, Vestweber D, Schindler H, Drenckhahn D. 2000. Cadherin interaction probed by atomic force microscopy. Proc Natl Acad Sci 97: 4005-4010.

Bellanger JM, Lazaro JB, Diriong S, Fernandez A, Lamb N, Debant A. 1998. The two guanine nucleotide exchange factor domains of Trio link the Racl and the RhoA pathways in vivo. Oncogene 16: 147-152.

Boulday G, Rudini N, Maddaluno L, Blecon A, Arnould M, Gaudric A, Chapon F, Adams RH, Dejana E, TournierLasserve E. 2011. Developmental timing of CCM2 loss influences cerebral cavernous malformations in mice. J Exp Med 208: 1835-1847.

Brasch J, Harrison OJ, Honig B, Shapiro L. 2012. Thinking outside the cell: How cadherins drive adhesion. Trends Cell Biol 22: 299-310.

Bravi L, Dejana E, Lampugnani MG. 2014. VE-cadherin at a glance. Cell Tissue Res 355: 515-522.

Bravi L, Rudini N, Cuttano R, Giampietro C, Maddaluno L, Ferrarini L, Adams RH, Corada M, Boulday G, TournierLasserve E, et al. 2015. Sulindac metabolites decrease cerebrovascular malformations in CCM3-knockout mice. Proc Natl Acad Sci 112: 8421-8426.

Bravi L, Malinverno M, Pisati F, Rudini N, Cuttano R, Pallini R, Martini M, Larocca LM, Locatelli M, Levi V, et al. 2016. Endothelial cells lining sporadic cerebral cavernous malformation cavernomas undergo endothelial-to-mesenchymal transition. Stroke 47: 886-890.

Broermann A, Winderlich M, Block H, Frye M, Rossaint J, Zarbock A, Cagna G, Linnepe R, Schulte D, Nottebaum AF, et al. 2011. Dissociation of VE-PTP from VE-cadherin is required for leukocyte extravasation and for VEGF-induced vascular permeability in vivo. J Exp Med 208: 2393-2401.

Cain RJ, Vanhaesebroeck B, Ridley AJ. 2010. The PI3K p110 $\alpha$ isoform regulates endothelial adherens junctions via Pyk2 and Rac1. J Cell Biol 188: 863-876.

Carmeliet P, Lampugnani MG, Moons L, Breviario F, Compernolle V, Bono F, Balconi G, Spagnuolo R, Oosthuyse B, Dewerchin M, et al. 1999. Targeted deficiency or cytosolic truncation of the VE-cadherin gene in mice impairs VEGF-mediated endothelial survival and angiogenesis. Cell 98: 147-157.

Chervin-Petinot A, Courcon M, Almagro S, Nicolas A, Grichine A, Grunwald D, Prandini MH, Huber P, 
M.G. Lampugnani et al.

Gulino-Debrac D. 2012. Epithelial protein lost in neoplasm (EPLIN) interacts with $\alpha$-catenin and actin filaments in endothelial cells and stabilizes vascular capillary network in vitro. J Biol Chem 287: 7556-7572.

Choi HJ, Zhang H, Park H, Choi KS, Lee HW, Agrawal V, Kim YM, Kwon YG. 2015. Yes-associated protein regulates endothelial cell contact-mediated expression of angiopoietin-2. Nat Commun 6: 6943.

Chrzanowska-Wodnicka M, White GC II, Quilliam LA, Whitehead KJ. 2015. Small GTPase Rap1 is essential for mouse development and formation of functional vasculature. PLOS ONE 10: e0145689.

Clatterbuck RE, Eberhart CG, Crain BJ, Rigamonti D. 2001. Ultrastructural and immunocytochemical evidence that an incompetent blood-brain barrier is related to the pathophysiology of cavernous malformations. J Neurol Neurosurg Psychiatry 71: 188-192.

Coon BG, Baeyens N, Han J, Budatha M, Ross TD, Fang JS, Yun S, Thomas JL, Schwartz MA. 2015. Intramembrane binding of VE-cadherin to VEGFR2 and VEGFR3 assembles the endothelial mechanosensory complex. J Cell Biol 208: 975-986.

Corada M, Mariotti M, Thurston G, Smith K, Kunkel R, Brockhaus M, Lampugnani MG, Martin-Padura I, Stoppacciaro A, Ruco L, et al. 1999. Vascular endothelialcadherin is an important determinant of microvascular integrity in vivo. Proc Natl Acad Sci 96: 9815-9820.

Cullere X, Plovie E, Bennett PM, MacRae CA, Mayadas TN. 2015. The cerebral cavernous malformation proteins CCM2L and CCM2 prevent the activation of the MAP kinase MEKK3. Proc Natl Acad Sci 112: 14284-14289.

Cuttano R, Rudini N, Bravi L, Corada M, Giampietro C, Papa E, Morini MF, Maddaluno L, Baeyens N, Adams RH, et al 2016. KLF4 is a key determinant in the development and progression of cerebral cavernous malformations. $E M B O$ Mol Med 8: 6-24.

de Kreuk BJ, Gingras AR, Knight JD, Liu JJ, Gingras AC, Ginsberg MH. 2016. Heart of glass anchors Rasip1 at endothelial cell-cell junctions to support vascular integrity. Elife 5: e11394.

Dejana E. 2004. Endothelial cell-cell junctions: Happy together. Nat Rev Mol Cell Biol 5: 261-270.

Dejana E, Giampietro C. 2012. Vascular endothelialcadherin and vascular stability. Curr Opin Hematol 19: 218-223.

Dejana E, Vestweber D. 2013. The role of VE-cadherin in vascular morphogenesis and permeability control. Prog Mol Biol Transl Sci 116: 119-144.

Dorland YL, Huveneers S. 2016. Cell-cell junctional mechanotransduction in endothelial remodeling. Cell Mol Life Sci 74: 279-292.

Draheim KM, Huet-Calderwood C, Simon B, Calderwood DA. 2017. Nuclear localization of integrin cytoplasmic domain-associated protein-1 (ICAP1) influences $\beta 1$-integrin activation and recruits Krev/interaction trapped-1 (KRIT1) to the nucleus. J Biol Chem 292: 1884-1898.

Dupont S, Morsut L, Aragona M, Enzo E, Giulitti S, Cordenonsi M, Zanconato F, Le Digabel J, Forcato M, Bicciato S et al. 2011. Role of YAP/TAZ in mechanotransduction. Nature 474: 179-183.
Eliceiri BP, Paul R, Schwartzberg PL, Hood JD, Leng J, Cheresh DA. 1999. Selective requirement for Src kinases during VEGF-induced angiogenesis and vascular permeability. Mol Cell 4: 915-924.

Fachinger G, Deutsch U, Risau W. 1999. Functional interaction of vascular endothelial-protein-tyrosine phosphatase with the angiopoietin receptor Tie-2. Oncogene 18: 59485953.

Fidalgo M, Fraile M, Pires A, Force T, Pombo C, Zalvide J. 2010. CCM3/PDCD10 stabilizes GCKIII proteins to promote Golgi assembly and cell orientation. J Cell Sci 123: 1274-1284.

Fisher OS, Boggon TJ. 2014. Signaling pathways and the cerebral cavernous malformations proteins: Lessons from structural biology. Cell Mol Life Sci 71: 1881-1892.

Francalanci F, Avolio M, De Luca E, Longo D, Menchise V, Guazzi P, Sgro F, Marino M, Goitre L, Balzac F, et al. 2009. Structural and functional differences between KRIT1A and KRIT1B isoforms: A framework for understanding CCM pathogenesis. Exp Cell Res 315: 285-303.

Frittoli E, Matteoli G, Palamidessi A, Mazzini E, Maddaluno L, Disanza A, Yang C, Svitkina T, Rescigno M, Scita G. 2011. The signaling adaptor Eps8 is an essential actin capping protein for dendritic cell migration. Immunity 35: 388-399.

Frye M, Dierkes M, Kuppers V, Vockel M, Tomm J, Zeuschner D, Rossaint J, Zarbock A, Koh GY, Peters K, et al. 2015. Interfering with VE-PTP stabilizes endothelial junctions in vivo via Tie- 2 in the absence of VE-cadherin. J Exp Med 212: 2267-2287.

Fukuhara S, Sako K, Minami T, Noda K, Kim HZ, Kodama T, Shibuya M, Takakura N, Koh GY, Mochizuki N. 2008. Differential function of Tie2 at cell-cell contacts and cell-substratum contacts regulated by angiopoietin-1. Nat Cell Biol 10: 513-526.

Galvagni F, Pennacchini S, Salameh A, Rocchigiani M, Neri F, Orlandini M, Petraglia F, Gotta S, Sardone GL, Matteucci G, et al. 2010. Endothelial cell adhesion to the extracellular matrix induces c-Src-dependent VEGFR-3 phosphorylation without the activation of the receptor intrinsic kinase activity. Circ Res 106: 1839-1848.

Gault J, Shenkar R, Recksiek P, Awad IA. 2005. Biallelic somatic and germ line CCM1 truncating mutations in a cerebral cavernous malformation lesion. Stroke 36: 872 874.

Gavard J, Gutkind JS. 2006. VEGF controls endothelial-cell permeability by promoting the beta-arrestin-dependent endocytosis of VE-cadherin. Nat Cell Biol 8: 1223-1234.

Ghosh CC, David S, Zhang R, Berghelli A, Milam K, Higgins SJ, Hunter J, Mukherjee A, Wei Y, Tran M, et al. 2016. Gene control of tyrosine kinase TIE2 and vascular manifestations of infections. Proc Natl Acad Sci 113: 2472-2477.

Giampietro C, Taddei A, Corada M, Sarra-Ferraris GM, Alcalay M, Cavallaro U, Orsenigo F, Lampugnani MG, Dejana E. 2012. Overlapping and divergent signaling pathways of $\mathrm{N}$-cadherin and VE-cadherin in endothelial cells. Blood 119: 2159-2170.

Giampietro C, Disanza A, Bravi L, Barrios-Rodiles M, Corada M, Frittoli E, Savorani C, Lampugnani MG, Boggetti B, Niessen C, et al. 2015. The actin-binding protein EPS8 
binds VE-cadherin and modulates YAP localization and signaling. J Cell Biol 211: 1177-1192.

Giannotta M, Trani M, Dejana E. 2013. VE-cadherin and endothelial adherens junctions: Active guardians of vascular integrity. Dev Cell 26: 441-454.

Gibson CC, Zhu W, Davis CT, Bowman-Kirigin JA, Chan AC, Ling J, Walker AE, Goitre L, Delle Monache S, Retta SF, et al. 2015. Strategy for identifying repurposed drugs for the treatment of cerebral cavernous malformation. Circulation 131: 289-299.

Gingras AR, Liu JJ, Ginsberg MH. 2012. Structural basis of the junctional anchorage of the cerebral cavernous malformations complex. J Cell Biol 199: 39-48.

Glading AJ, Ginsberg MH. 2010. Rap1 and its effector KRIT1/CCM1 regulate $\beta$-catenin signaling. Dis Model Mech 3: 73-83.

Glading A, Han J, Stockton RA, Ginsberg MH. 2007. KRIT1/CCM1 is a Rap1 effector that regulates endothelial cellcell junctions. J Cell Biol 179: 247-254.

Gong H, Gao X, Feng S, Siddiqui MR, Garcia A, Bonini MG, Komarova Y, Vogel SM, Mehta D, Malik AB. 2014. Evidence of a common mechanism of disassembly of adherens junctions through G $\alpha 13$ targeting of VE-cadherin. J Exp Med 211: 579-591.

Gong H, Rehman J, Tang H, Wary K, Mittal M, Chaturvedi P, Zhao YY, Komarova YA, Vogel SM, Malik AB. 2015. HIF2 $\alpha$ signaling inhibits adherens junctional disruption in acute lung injury. J Clin Invest 125: 652-664.

Gordon EJ, Fukuhara D, Westrom S, Padhan N, Sjostrom EO, van Meeteren L, He L, Orsenigo F, Dejana E, Bentley $\mathrm{K}$, et al. 2016. The endothelial adaptor molecule TSAd is required for VEGF-induced angiogenic sprouting through junctional c-Src activation. Sci Signal 9: ra72.

Gossage L, Eisen T, Maher ER. 2015. VHL, the story of a tumour suppressor gene. Nat Rev Cancer 15: 55-64.

Gurnik S, Devraj K, Macas J, Yamaji M, Starke J, Scholz A, Sommer K, Di Tacchio M, Vutukuri R, Beck H, et al. 2016. Angiopoietin-2-induced blood-brain barrier compromise and increased stroke size are rescued by VE-PTPdependent restoration of Tie2 signaling. Acta Neuropathol 131: 753-773.

Harrison OJ, Jin X, Hong S, Bahna F, Ahlsen G, Brasch J, Wu Y, Vendome J, Felsovalyi K, Hampton CM, et al. 2011. The extracellular architecture of adherens junctions revealed by crystal structures of type I cadherins. Structure 19: $244-256$

Hayashi M, Majumdar A, Li X, Adler J, Sun Z, Vertuani S, Hellberg C, Mellberg S, Koch S, Dimberg A, et al. 2013. VE-PTP regulates VEGFR2 activity in stalk cells to establish endothelial cell polarity and lumen formation. Nat Commun 4: 1672.

He Y, Zhang H, Yu L, Gunel M, Boggon TJ, Chen H, Min W. 2010. Stabilization of VEGFR2 signaling by cerebral cavernous malformation 3 is critical for vascular development. Sci Signal 3: ra26.

Heemskerk N, van Rijssel J, van Buul JD. 2014. Rho-GTPase signaling in leukocyte extravasation: an endothelial point of view. Cell Adh Migr 8: 67-75.

Heemskerk N, Schimmel L, Oort C, van Rijssel J, Yin T, Ma B, van Unen J, Pitter B, Huveneers S, Goedhart J, et al. 2016. F-actin-rich contractile endothelial pores prevent vascular leakage during leukocyte diapedesis through local RhoA signalling. Nat Commun 7: 10493.

Hertzog M, Milanesi F, Hazelwood L, Disanza A, Liu H, Perlade E, Malabarba MG, Pasqualato S, Maiolica A, Confalonieri S, et al. 2010. Molecular basis for the dual function of Eps8 on actin dynamics: Bundling and capping. PLoS Biol 8: e1000387.

Huveneers S, Oldenburg J, Spanjaard E, van der Krogt G, Grigoriev I, Akhmanova A, Rehmann H, de Rooij J. 2012. Vinculin associates with endothelial VE-cadherin junctions to control force-dependent remodeling. J Cell Biol 196: 641-652.

Jin ZG, Ueba H, Tanimoto T, Lungu AO, Frame MD, Berk BC. 2003. Ligand-independent activation of vascular endothelial growth factor receptor 2 by fluid shear stress regulates activation of endothelial nitric oxide synthase. Circ Res 93: 354-363.

Kam Y, Quaranta V. 2009. Cadherin-bound $\beta$-catenin feeds into the Wnt pathway upon adherens junctions dissociation: Evidence for an intersection between $\beta$-catenin pools. PLoS ONE 4: e4580.

Kean MJ, Ceccarelli DF, Goudreault M, Sanches M, Tate S, Larsen B, Gibson LC, Derry WB, Scott IC, Pelletier L, et al. 2011. Structure-function analysis of core STRIPAK proteins: A signaling complex implicated in Golgi polarization. J Biol Chem 286: 25065-25075.

Kelly E, Bailey CP, Henderson G. 2008. Agonist-selective mechanisms of GPCR desensitization. Br J Pharmacol 153: S379-S388.

Kleaveland B, Zheng X, Liu JJ, Blum Y, Tung JJ, Zou Z, Sweeney SM, Chen M, Guo L, Lu MM, et al. 2009. Regulation of cardiovascular development and integrity by the heart of glass-cerebral cavernous malformation protein pathway. Nat Med 15: 169-176.

Kolluru GK, Majumder S, Chatterjee S. 2014. Rho-kinase as a therapeutic target in vascular diseases: Striking nitric oxide signaling. Nitric Oxide 43: 45-54.

Kooistra MR, Corada M, Dejana E, Bos JL. 2005. Epac1 regulates integrity of endothelial cell junctions through VE-cadherin. FEBS Lett 579: 4966-4972.

Lampugnani MG, Orsenigo F, Gagliani MC, Tacchetti C, Dejana E. 2006. Vascular endothelial cadherin controls VEGFR-2 internalization and signaling from intracellular compartments. J Cell Biol 174: 593-604.

Lampugnani MG, Orsenigo F, Rudini N, Maddaluno L, Boulday G, Chapon F, Dejana E. 2010. CCM1 regulates vascular-lumen organization by inducing endothelial polarity. J Cell Sci 123(Pt 7): 1073-1080.

Lezoualc'h F, Fazal L, Laudette M, Conte C. 2016. Cyclic AMP sensor EPAC proteins and their role in cardiovascular function and disease. Circ Res 118: 881-897.

Li X, Padhan N, Sjostrom EO, Roche FP, Testini C, Honkura N, Sainz-Jaspeado M, Gordon E, Bentley K, Philippides A, et al. 2016. VEGFR2 pY949 signalling regulates adherens junction integrity and metastatic spread. Nat Commun 7: 11017.

Maddaluno L, Rudini N, Cuttano R, Bravi L, Giampietro C, Corada M, Ferrarini L, Orsenigo F, Papa E, Boulday G, et al. 2013. EndMT contributes to the onset and progression of cerebral cavernous malformations. Nature 498: 492496. 
M.G. Lampugnani et al.

Marcos-Ramiro B, Garcia-Weber D, Millan J. 2014. TNFinduced endothelial barrier disruption: Beyond actin and Rho. Thromb Haemost 112: 1088-1102.

McDonald DA, Shi C, Shenkar R, Stockton RA, Liu F, Ginsberg MH, Marchuk DA, Awad IA. 2012. Fasudil decreases lesion burden in a murine model of cerebral cavernous malformation disease. Stroke 43: 571-574.

McDonald DA, Shi C, Shenkar R, Gallione CJ, Akers AL, Li S, De Castro N, Berg MJ, Corcoran DL, Awad IA, et al. 2014. Lesions from patients with sporadic cerebral cavernous malformations harbor somatic mutations in the CCM genes: Evidence for a common biochemical pathway for CCM pathogenesis. Hum Mol Genet 23: 4357-4370.

Mellberg S, Dimberg A, Bahram F, Hayashi M, Rennel E, Ameur A, Westholm JO, Larsson E, Lindahl P, Cross MJ, et al. 2009. Transcriptional profiling reveals a critical role for tyrosine phosphatase VE-PTP in regulation of VEGFR2 activity and endothelial cell morphogenesis. FASEB J 23: 1490-1502.

Millan J, Cain RJ, Reglero-Real N, Bigarella C, Marcos-Ramiro B, Fernandez-Martin L, Correas I, Ridley AJ. 2010. Adherens junctions connect stress fibres between adjacent endothelial cells. BMC Biol 8: 11.

Montero-Balaguer M, Swirsding K, Orsenigo F, Cotelli F, Mione M, Dejana E. 2009. Stable vascular connections and remodeling require full expression of VE-cadherin in zebrafish embryos. PLoS ONE 4: e5772.

Morin-Kensicki EM, Boone BN, Howell M, Stonebraker JR, Teed J, Alb JG, Magnuson TR, O’Neal W, Milgram SL. 2006. Defects in yolk sac vasculogenesis, chorioallantoic fusion, and embryonic axis elongation in mice with targeted disruption of Yap65. Mol Cell Biol 26: 77-87.

Muller WA. 2016. Transendothelial migration: Unifying principles from the endothelial perspective. Immunol Rev 273: 61-75.

Navarro P, Caveda L, Breviario F, Mandoteanu I, Lampugnani MG, Dejana E. 1995. Catenin-dependent and -independent functions of vascular endothelial cadherin. J Biol Chem 270: 30965-30972.

Nawroth R, Poell G, Ranft A, Kloep S, Samulowitz U, Fachinger G, Golding M, Shima DT, Deutsch U, Vestweber D. 2002. VE-PTP and VE-cadherin ectodomains interact to facilitate regulation of phosphorylation and cell contacts. EMBO J 21: 4885-4895.

Nguyen HL, Boon LM, Vikkula M. 2014. Genetics of vascular malformations. Semin Pediatr Surg 23: 221-226.

Niessen CM, Gottardi CJ. 2008. Molecular components of the adherens junction. Biochim Biophys Acta 1778: 562571.

Nottebaum AF, Cagna G, Winderlich M, Gamp AC, Linnepe R, Polaschegg C, Filippova K, Lyck R, Engelhardt B, Kamenyeva O, et al. 2008. VE-PTP maintains the endothelial barrier via plakoglobin and becomes dissociated from VE-cadherin by leukocytes and by VEGF. J Exp Med 205: 2929-2945.

Orsenigo F, Giampietro C, Ferrari A, Corada M, Galaup A, Sigismund S, Ristagno G, Maddaluno L, Koh GY, Franco D, et al. 2012. Phosphorylation of VE-cadherin is modulated by haemodynamic forces and contributes to the regulation of vascular permeability in vivo. Nat Commun 3: 1208 .
Pannekoek WJ, van Dijk JJ, Chan OY, Huveneers S, Linnemann JR, Spanjaard E, Brouwer PM, van der Meer AJ, Zwartkruis FJ, Rehmann H, et al. 2011. Epac1 and PDZGEF cooperate in Rap1 mediated endothelial junction control. Cell Signal 23: 2056-2064.

Pannekoek WJ, Post A, Bos JL. 2014. Rap1 signaling in endothelial barrier control. Cell Adh Migr 8: 100-107.

Park-Windhol C, D’Amore PA. 2016. Disorders of vascular permeability. Annu Rev Pathol 11: 251-281.

Post A, Pannekoek WJ, Ross SH, Verlaan I, Brouwer PM, Bos JL. 2013. Rasip1 mediates Rap1 regulation of Rho in endothelial barrier function through ArhGAP29. Proc Natl Acad Sci 110: 11427-11432.

Post A, Pannekoek WJ, Ponsioen B, Vliem MJ, Bos JL. 2015. Rap1 spatially controls ArhGAP29 to inhibit Rho signaling during endothelial barrier regulation. Mol Cell Biol 35: 2495-2502.

Riant F, Bergametti F, Fournier HD, Chapon F, MichalakProvost S, Cecillon M, Lejeune P, Hosseini H, Choe C, Orth M, et al. 2013. CCM3 mutations are associated with early-onset cerebral hemorrhage and multiple meningiomas. Mol Syndromol 4: 165-172.

Rudini N, Felici A, Giampietro C, Lampugnani M, Corada M, Swirsding K, Garre M, Liebner S, Letarte M, ten Dijke $\mathrm{P}$, et al. 2008. VE-cadherin is a critical endothelial regulator of TGF- $\beta$ signalling. EMBO J 27: 993-1004.

Saharinen P, Eklund L, Miettinen J, Wirkkala R, Anisimov A, Winderlich M, Nottebaum A, Vestweber D, Deutsch U, Koh GY, et al. 2008. Angiopoietins assemble distinct Tie2 signalling complexes in endothelial cell-cell and cell-matrix contacts. Nat Cell Biol 10: 527-537.

Schaefer A, Hordijk PL. 2015. Cell-stiffness-induced mechanosignaling-A key driver of leukocyte transendothelial migration. J Cell Sci 128: 2221-2230.

Schulte D, Kuppers V, Dartsch N, Broermann A, Li H, Zarbock A, Kamenyeva O, Kiefer F, Khandoga A, Massberg S, et al. 2011. Stabilizing the VE-cadherin-catenin complex blocks leukocyte extravasation and vascular permeability. EMBO J 30: 4157-4170.

Schwede F, Bertinetti D, Langerijs CN, Hadders MA, Wienk $\mathrm{H}$, Ellenbroek JH, de Koning EJ, Bos JL, Herberg FW, Genieser HG, et al. 2015. Structure-guided design of selective Epac1 and Epac2 agonists. PLoS Biol 13: e1002038.

Scita G, Nordstrom J, Carbone R, Tenca P, Giardina G, Gutkind S, Bjarnegard M, Betsholtz C, Di Fiore PP. 1999. EPS8 and E3B1 transduce signals from Ras to Rac. Nature 401: 290-293.

Shen J, Frye M, Lee BL, Reinardy JL, McClung JM, Ding K, Kojima M, Xia H, Seidel C, Lima e Silva R, et al. 2014. Targeting VE-PTP activates TIE2 and stabilizes the ocular vasculature. J Clin Invest 124: 4564-4576.

Shenkar R, Shi C, Austin C, Moore T, Lightle R, Cao Y, Zhang L, Wu M, Zeineddine HA, Girard R, et al. 2017. RhoA kinase inhibition with fasudil versus simvastatin in murine models of cerebral cavernous malformations. Stroke 48: 187-194.

Sieiro D, Rios AC, Hirst CE, Marcelle C. 2016. Cytoplasmic $\mathrm{NOTCH}$ and membrane-derived beta-catenin link cell fate choice to epithelial-mesenchymal transition during myogenesis. Elife 5: e14847 
Sivaraj KK, Takefuji M, Schmidt I, Adams RH, Offermanns S, Wettschureck N. 2013. $\mathrm{G}_{13}$ controls angiogenesis through regulation of VEGFR-2 expression. Dev Cell 25: 427-434.

Stockton RA, Shenkar R, Awad IA, Ginsberg MH. 2010 Cerebral cavernous malformations proteins inhibit Rho kinase to stabilize vascular integrity. J Exp Med 207: 881896.

Sun Z, Li X, Massena S, Kutschera S, Padhan N, Gualandi L, Sundvold-Gjerstad V, Gustafsson K, Choy WW, Zang G, et al. 2012. VEGFR2 induces c-Src signaling and vascular permeability in vivo via the adaptor protein TSAd. J Exp Med 209: 1363-1377.

Taddei A, Giampietro C, Conti A, Orsenigo F, Breviario F, Pirazzoli V, Potente M, Daly C, Dimmeler S, Dejana E. 2008. Endothelial adherens junctions control tight junctions by VE-cadherin-mediated upregulation of claudin5. Nat Cell Biol 10: 923-934.

Timmerman I, Heemskerk N, Kroon J, Schaefer A, van Rijssel J, Hoogenboezem M, van Unen J, Goedhart J, Gadella TW Jr, Yin T, et al. 2015. A local VE-cadherin and Triobased signaling complex stabilizes endothelial junctions through Rac1. J Cell Sci 128: 3514.

Timmerman I, Daniel AE, Kroon J, van Buul JD. 2016. Leukocytes crossing the endothelium: a matter of communication. Int Rev Cell Mol Biol 322: 281-329.

Tzima E, Irani-Tehrani M, Kiosses WB, Dejana E, Schultz DA, Engelhardt B, Cao G, DeLisser H, Schwartz MA. 2005. A mechanosensory complex that mediates the endothelial cell response to fluid shear stress. Nature 437: 426-431.

van Buul JD, Timmerman I. 2016. Small Rho GTPase-mediated actin dynamics at endothelial adherens junctions. Small GTPases 7: 21-31.

Van Rijssel J, Timmerman I, Van Alphen FP, Hoogenboezem M, Korchynskyi O, Geerts D, Geissler J, Reedquist KA, Niessen HW, Van Buul JD. 2013. The Rho-GEF trio regulates a novel pro-inflammatory pathway through the transcription factor Ets2. Biol Open 2: 569-579.

Varelas X. 2014. The Hippo pathway effectors TAZ and YAP in development, homeostasis and disease. Development 141: 1614-1626.

Vestweber D, Winderlich M, Cagna G, Nottebaum AF. 2009. Cell adhesion dynamics at endothelial junctions: VE-cadherin as a major player. Trends Cell Biol 19: 8-15.

Vestweber D, Wessel F, Nottebaum AF. 2014. Similarities and differences in the regulation of leukocyte extravasation and vascular permeability. Semin Immunopathol 36: 177-192.

Vockel M, Vestweber D. 2013. How T cells trigger the dissociation of the endothelial receptor phosphatase VEPTP from VE-cadherin. Blood 122: 2512-2522.

Vorbrodt AW, Dobrogowska DH. 2003. Molecular anatomy of intercellular junctions in brain endothelial and epithelial barriers: Electron microscopist's view. Brain Res Brain Res Rev 42: 221-242.

Voss K, Stahl S, Schleider E, Ullrich S, Nickel J, Mueller TD, Felbor U. 2007. CCM3 interacts with CCM2 indicating common pathogenesis for cerebral cavernous malformations. Neurogenetics 8: 249-256.
Voss K, Stahl S, Hogan BM, Reinders J, Schleider E, SchulteMerker S, Felbor U. 2009. Functional analyses of human and zebrafish 18-amino acid in-frame deletion pave the way for domain mapping of the cerebral cavernous malformation 3 protein. Hum Mutat 30: 1003-1011.

Wessel F, Winderlich M, Holm M, Frye M, Rivera-Galdos R, Vockel M, Linnepe R, Ipe U, Stadtmann A, Zarbock A, et al. 2014. Leukocyte extravasation and vascular permeability are each controlled in vivo by different tyrosine residues of VE-cadherin. Nat Immunol 15(3): 223-230.

Whitehead KJ, Chan AC, Navankasattusas S, Koh W, London NR, Ling J, Mayo AH, Drakos SG, Jones CA, Zhu W, et al. 2009. The cerebral cavernous malformation signaling pathway promotes vascular integrity via Rho GTPases. Nat Med 15: 177-184.

Wilson CW, Ye W. 2014. Regulation of vascular endothelial junction stability and remodeling through Rap1-Rasip1 signaling. Cell Adh Migr 8: 76-83.

Wilson CW, Parker LH, Hall CJ, Smyczek T, Mak J, Crow A, Posthuma G, De Maziere A, Sagolla M, Chalouni C, et al. 2013. Rasip1 regulates vertebrate vascular endothelial junction stability through Epac1-Rap1 signaling. Blood 122: 3678-3690.

Wittchen ES, Hartnett ME. 2011. The small GTPase Rap1 is a novel regulator of RPE cell barrier function. Invest Ophthalmol Vis Sci 52: 7455-7463.

Wittchen ES, Worthylake RA, Kelly P, Casey PJ, Quilliam LA, Burridge K. 2005. Rap1 GTPase inhibits leukocyte transmigration by promoting endothelial barrier function. J Biol Chem 280: 11675-11682.

Xu K, Sacharidou A, Fu S, Chong DC, Skaug B, Chen ZJ, Davis GE, Cleaver O. 2011. Blood vessel tubulogenesis requires Rasip1 regulation of GTPase signaling. Dev Cell 20: 526-539.

Yap AS, Gomez GA, Parton RG. 2015. Adherens junctions revisualized: Organizing cadherins as nanoassemblies. Dev Cell 35: 12-20.

Zhao Z, Manser E. 2015. Myotonic dystrophy kinase-related Cdc42-binding kinases (MRCK), the ROCK-like effectors of Cdc42 and Rac1. Small GTPases 6: 81-88.

Zheng X, Xu C, Di Lorenzo A, Kleaveland B, Zou Z, Seiler C, Chen M, Cheng L, Xiao J, He J, et al. 2010. CCM3 signaling through sterile 20-like kinases plays an essential role during zebrafish cardiovascular development and cerebral cavernous malformations. J Clin Invest 120: 2795-2804.

Zheng X, Riant F, Bergametti F, Myers CD, Tang AT, Kleaveland B, Pan W, Yang J, Tournier-Lasserve E, Kahn ML. 2014. Cerebral cavernous malformations arise independent of the heart of glass receptor. Stroke 45: 1505-1509.

Zhou HJ, Qin L, Zhang H, Tang W, Ji W, He Y, Liang X, Wang Z, Yuan Q, Vortmeyer A, et al. 2016a. Endothelial exocytosis of angiopoietin-2 resulting from CCM3 deficiency contributes to cerebral cavernous malformation. Nat Med. 22: 1033-1042.

Zhou Z, Tang AT, Wong WY, Bamezai S, Goddard LM, Shenkar R, Zhou S, Yang J, Wright AC, Foley M, et al. 2016b. Cerebral cavernous malformations arise from endothelial gain of MEKK3-KLF2/4 signalling. Nature 532: $122-126$. 


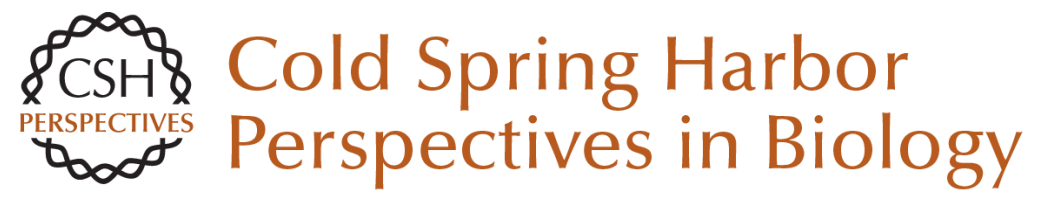

\title{
Vascular Endothelial (VE)-Cadherin, Endothelial Adherens Junctions, and Vascular Disease
}

\author{
Maria Grazia Lampugnani, Elisabetta Dejana and Costanza Giampietro
}

Cold Spring Harb Perspect Biol 2018; doi: 10.1101/cshperspect.a029322 originally published online August 29, 2017

\section{Subject Collection Cell-Cell Junctions}

Vascular Endothelial (VE)-Cadherin, Endothelial

Adherens Junctions, and Vascular Disease Maria Grazia Lampugnani, Elisabetta Dejana and Costanza Giampietro

Adherens Junctions and Desmosomes

Coordinate Mechanics and Signaling to

Orchestrate Tissue Morphogenesis and Function:

An Evolutionary Perspective

Matthias Rübsam, Joshua A. Broussard, Sara A. Wickström, et al.

\section{Cell-Cell Contact and Receptor Tyrosine Kinase}

Signaling

Christine Chiasson-MacKenzie and Andrea I. McClatchey

Hold Me, but Not Too Tight--Endothelial Cell-Cell Junctions in Angiogenesis

Anna Szymborska and Holger Gerhardt

Connexins and Disease

Mario Delmar, Dale W. Laird, Christian C. Naus, et al.

Cell Junctions in Hippo Signaling Ruchan Karaman and Georg Halder
Signaling by Small GTPases at Cell-Cell Junctions: Protein Interactions Building Control and Networks Vania Braga

Making Connections: Guidance Cues and

Receptors at Nonneural Cell-Cell Junctions lan V. Beamish, Lindsay Hinck and Timothy E. Kennedy

The Cadherin Superfamily in Neural Circuit Assembly James $D$. Jontes

Mechanosensing and Mechanotransduction at Cell-Cell Junctions Alpha S. Yap, Kinga Duszyc and Virgile Viasnoff

Beyond Cell-Cell Adhesion: Sensational

Cadherins for Hearing and Balance Avinash Jaiganesh, Yoshie Narui, Raul Araya-Secchi, et al.

Cell-Cell Junctions Organize Structural and Signaling Networks Miguel A. Garcia, W. James Nelson and Natalie Chavez

For additional articles in this collection, see http://cshperspectives.cshlp.org/cgi/collection/

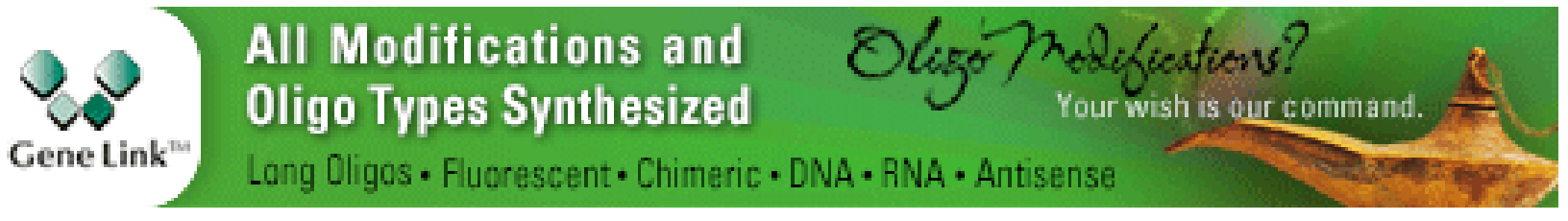


Loss of E-Cadherin-Dependent Cell-Cell Adhesion and the Development and Progression of Cancer Heather C. Bruner and Patrick W.B. Derksen

Desmosomes and Intermediate Filaments: Their Consequences for Tissue Mechanics

Mechthild Hatzfeld, René Keil and Thomas M. Magin
Cell Biology of Tight Junction Barrier Regulation and Mucosal Disease

Aaron Buckley and Jerrold R. Turner

Integration of Cadherin Adhesion and

Cytoskeleton at Adherens Junctions

René Marc Mège and Noboru Ishiyama

For additional articles in this collection, see http://cshperspectives.cshlp.org/cgi/collection/

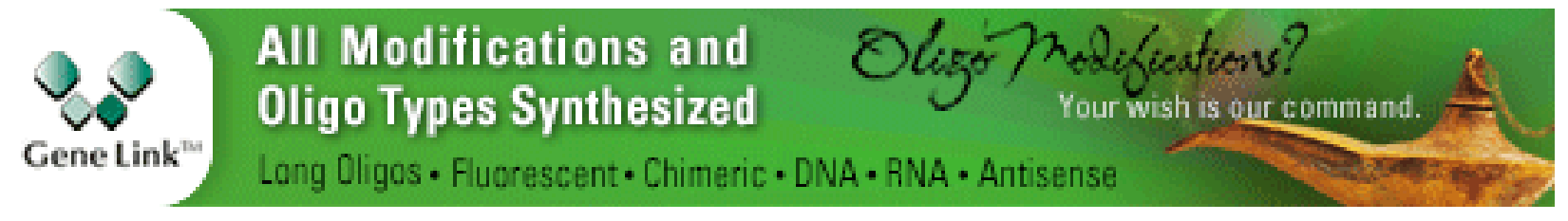

Copyright @ 2018 Cold Spring Harbor Laboratory Press; all rights reserved 